\title{
Isolation and Characterization of a cDNA Clone Encoding the 60-kD Component of the Human SS-A/Ro Ribonucleoprotein Autoantigen
}

\author{
Eldad Ben-Chetrit, Barbara J. Gandy, Eng M. Tan, and Kevin F. Sullivan \\ W. M. Keck Autoimmune Disease Center, Department of Basic and Clinical Research, Research Institute of Scripps Clinic, \\ La Jolla, California 92037
}

\begin{abstract}
SS-A/Ro is a nucleocytoplasmic ribonucleoprotein (RNP) particle that is a common target of autoimmune response in Sjögren's syndrome (SS) and systemic lupus erythematosus (SLE). Previously, SS-A/Ro has been shown to be composed of at least two polypeptide antigens of 60 and $52 \mathrm{kD}$ noncovalently associated with a set of small RNAs, designated Y1-Y5. A serum from an SS patient was selected to screen a $\lambda$ gt11 cDNA library constructed from human $T$ cell lymphoblastic leukemia (MOLT-4) mRNA. An immunoreactive clone was isolated that possessed a 1.8-kb cDNA insert. In vitro transcription and translation of the cDNA resulted in the synthesis of a 57.5-kD polypeptide which was specifically immunoprecipitated by SS-A/Ro antisera. The identity of the cDNA encoded protein as the 60-kD SS-A/Ro antigen was established by proteolytic peptide mapping of the cDNA-encoded protein and the 60-kD HeLa cell antigen. The sequence of the cDNA shows that the 60-kD SS-A/Ro protein possesses both RNA binding protein consensus sequences and a single zinc-finger motif. Recombinant SS-A/Ro antigen produced in bacteria proved to be a sensitive and specific reagent for detection of anti-SS-A/Ro antibodies in patient sera. The availability of the 60-kD SS-A/Ro cDNA will enable detailed analysis of the molecular structure and function of the SS-A/Ro RNP particle and its role in autoimmune pathology.
\end{abstract}

\section{Introduction}

Systemic autoimmune diseases are characterized by circulating autoantibodies directed against a variety of pormal nuclear proteins and nucleoprotein complexes (1). Most antinuclear autoantibodies, with the notable exception of antibodies to DNA (2), do not appear to play a direct role in the pathogenic mechanisms of systemic autoimmune diseases. Nevertheless, the presence of specific autoantibodies is highly characteristic of certain clinical entities. Analysis of the antigen and antibody components of autoimmune disorders is thus motivated by the hypothesis that they represent markers of the underlying immune disorder. Understanding how autoantibodies arise in

Dr. Ben-Chetrit's present address is Hadassah University Hospital, Jerusalem, Israel.

Address reprint requests to Dr. Eng M. Tan, Department of Basic and Clinical Research, BCR6, Research Institute of Scripps Clinic, 10666 North Torrey Pines Road, La Jolla, CA 92037.

Received for publication 20 July 1988 and in revised form 21 October 1988.

J. Clin. Invest.

(C) The American Society for Clinical Investigation, Inc.

$0021-9738 / 89 / 04 / 1284 / 09 \$ 2.00$

Volume 83, April 1989, 1284-1292 conjunction with specific disease states is expected to yield clues into the etiological mechanisms and, ultimately, pathological mechanisms that are responsible for systemic autoimmune disorders.

The SS-A/Ro antigen is a common target of autoimmune response in a number of systemic autoimmune diseases, including Sjögren's syndrome (SS), ${ }^{1}$ systemic lupus erythematosus (SLE), subacute cutaneous lupus, and neonatal lupus (1). SS-A/Ro has been defined biochemically as an RNA-protein complex composed of polypeptides noncovalently associated with a family of small RNAs, designated Y1-Y5 (3). The protein components of SS-A/Ro ribonucleoprotein (RNP) particles make up at least two immunologically distinct proteins of 60 and $52 \mathrm{kD}(3,4)$. Experiments using monospecific autoantibodies against the 52- and $60-\mathrm{kD}$ SS-A/Ro antigens have shown that both polypeptides are localized in the nucleus, and are associated with the same spectrum of Y-RNAs. These data indicate that the 52- and the $60-\mathrm{kD}$ polypeptides are components of a single class of intracellular RNP particle $(3,4)$.

The biological functions of SS-A/Ro Y-RNP particles are not known, nor is it understood why the SS-A/Ro particle is a target for autoimmune reaction in rheumatic diseases. To gain insight into the biological and clinical significance of the SS-A/Ro RNP particle, we have isolated a cDNA clone containing the complete or nearly complete protein coding sequence of the $60-\mathrm{kD}$ SS-A/Ro antigen. In this report, we describe the characterization of this CDNA, the sequence of the 60-kD SS-A/Ro polypeptide and demonstrate the utility of a bacterially expressed $60-\mathrm{kD}$ SS-A/Ro antigen for the sensitive and specific analysis of SS-A/Ro antibodies in sera from patients with autoimmune diseases.

\section{Methods}

Human sera. Sera were obtained from patients with SLE or SS who were treated at the Green Hospital of Scripps Clinic. Sera from laboratory personnel served as controls.

Cell lines. HeLa (ATCC CCL 2.2; American Type Culture Collection, Rockville, MD) and MOLT-4 (human T cell lymphoblastic leukemia) (ATCC CRL 1582) cells were cultured and prepared for electrophoresis and immunoblotting as previously described (4).

Immunoblotting. Electrophoretic blotting was performed according to the method of Towbin et al. (5) with modifications. In brief, proteins were separated on $15 \%$ polyacrylamide/SDS gel and were electrotransferred to nitrocellulose. Nitrocellulose sheets were blocked by incubation for $1 \mathrm{~h}$ in PBS with 0.5\% Tween-20 (PBS-T) and 3\% nonfat dried milk and then incubated with sera (1:100-1:200 dilution) at room temperature for $1 \mathrm{~h}$. Filters were washed for $1 \mathrm{~h}$ with PBS-T and bound IgG was detected with ${ }^{125} \mathrm{I}$-protein A diluted to $2 \times 10^{5}$ $\mathrm{cpm} / \mathrm{ml}$ in PBS-T with $3 \%$ dried milk (ICN Biochemicals, Irvine, CA).

1. Abbreviations used in this paper: RNP, ribonucleoprotein; SS, Sjogren's syndrome; WT, wild type; NBRF, National Biomedical Research Foundation. 
Immunoprecipitation. Labeled cellular antigens and in vitro translated proteins were immunoprecipitated by antisera using protein ASepharose (Pharmacia Fine Chemicals, Piscataway, NJ) as described (6). The polypeptides were eluted by boiling in SDS-gel sample buffer for analysis on $15 \%$ polyacrylamide/SDS gels.

Affinity-purified antibodies. Anti-SS-A/Ro and anti-SS-B/La antibodies were affinity purified from nitrocellulose-bound antigens using the method of Olmsted (7). HeLa cell extract was resolved by electrophoresis and blotted to nitrocellulose and used as a source of human antigens. $\lambda \mathrm{gt} 11 \mathrm{cDNA}$ encoded antigens were induced from phage plaques and adsorbed to isopropyl- $\beta$-thiogalactopyranoside- (IPTG) saturated nitrocellulose filters. Filters were incubated with antiserum for $1 \mathrm{~h}$ and extensively washed. Bound antibodies were eluted in $0.2 \mathrm{M}$ glycine, $\mathrm{pH} 2.7$, and immediately neutralized by addition of $1 \mathrm{M}$ Tris, pH 9.0. After dialysis against PBS, the antibodies were concentrated using polyethylene glycol.

Screening of expression library with antibody probes. A high titer SS-A/Ro antiserum containing antibodies against both the 60 - and the 52-kD SS-A/Ro antigens was used in a dilution of 1:300 to screen a MOLT-4 cDNA library constructed in $\lambda$ gt 11 (8). Immunological screening of the library was performed essentially by the method of Young and Davis (8). Induction with IPTG saturated nitrocellulose filters was performed in duplicate. After transfer of the induced proteins to nitrocellulose, immunological detection was performed as described above.

Production of recombinant cDNA-encoded antigen in bacteria. Two bacterial expression systems were used for analysis of recombinant SS-A/Ro antigen. $\lambda$ gt 11 lysogens were constructed in Escherichia coli (Y1089) as previously described (9). Preparation of fusion protein from $25-\mathrm{ml}$ cultures was performed essentially by the method of Young and Davis (8). Induced cells were harvested, washed, and resuspended in $3 \%$ of the original volume of STE $(100 \mathrm{mM} \mathrm{NaCl}, 10 \mathrm{mM}$ Tris C14. pH 8.0, $1 \mathrm{mM}$ EDTA) containing $50 \mu \mathrm{g} / \mathrm{ml}$ lysozyme (Sigma Chemical Co., St. Louis, MO) and incubated for $5 \mathrm{~min}$ on ice. After freezing and thawing, the lysate was adjusted to $10 \mu \mathrm{g} / \mathrm{ml}$ DNase (Boehringer, Mannheim, FRG), $1 \%$ Triton-X 100 and to $1 \mathrm{mM} \mathrm{MgCl}_{2}$ and incubated for $10 \mathrm{~min}$ at room temperature. Finally an equal volume of SDS-gel sample buffer was added and samples were boiled for 3 min and stored at $-20^{\circ} \mathrm{C}$ for further analysis.

In another series of experiments, the cloned cDNA $5.1_{\mathrm{a}}$ was inserted into the $E$. coli trpE based fusion protein vector, pATH 11 (kindly provided by Dr. T. J. Koerner, Duke University, Durham, NC), and expressed in E. coli RR-1 (10). Fusion protein expression in bacterial cultures containing pATH 11 constructs was induced with 5 -indolacrylic acid as described (9). The harvested bacteria were then processed as above.

$R N A$ transcription and in vitro translation. The Eco RI insert of cDNA $5.1_{\mathrm{a}}$ was subcloned into the $\mathrm{T}_{3} / \mathrm{T}_{7}$ promoter plasmid Bluescript (Stratagene, La Jolla, CA). The resultant plasmid, p5.1 $1_{\mathrm{a}}$, was linearized by restriction enzyme digestion on either the $5^{\prime}$ or the $3^{\prime}$ side of the cDNA insert and RNA was transcribed in vitro from either strand of the cDNA using T3 or T7 RNA polymerase (Stratagene), respectively (11). As a control, a cDNA encoding a portion of human $\beta$-glucocerebrosidase (kindly provided by Dr. E. Beutler, Scripps Clinic) was transcribed in the same system. The RNAs were translated in vitro in a rabbit reticulocyte lysate (Promega-Biotec, Madison, WI) in the presence of $\left[{ }^{35}\right.$ S]methionine (New England Nuclear, Boston, MA) according to the manufacturers instructions. Products of in vitro translation were stored at $-70^{\circ} \mathrm{C}$ for further analysis.

Peptide mapping. HeLa cell proteins and CDNA 5.1 $\mathrm{a}$-encoded antigen were labeled with $\left[{ }^{35} S\right]$ methionine in vivo or in vitro, respectively. Proteolytic peptide mapping was performed as described (12) with modifications. Labeled antigens were purified by immunoprecipitation with specific anti-60-kD serum and resolved on SDS-PAGE. Strips corresponding to the $M_{\mathrm{r}}$ region from 30 to $90 \mathrm{kD}$ were excised from the gel and mounted orthogonally on top of a second gel and then overlaid with 1.0-10 $\mu \mathrm{g}$ Staphylococcus aureus V8 protease (Sigma
Chemical Co.). As a control, duplicate gels were run in the absence of protease. Electrophoresis was initiated at $80 \mathrm{~V}$ until the dye entered the stacking gel. Proteolysis occurred in the stacking gel for $30 \mathrm{~min}$ and electrophoresis was continued. Peptides were visualized by fluorography.

DNA sequencing and analysis. The sequence of $\mathrm{cDNA} 5.1_{\mathrm{a}}$ was determined on both strands using a set of Bal-31 (Promega-Biotec) deletions or restriction fragments subcloned into M13 vectors as described previously (13). Sequence analysis was performed by the dideoxy chain termination method (14) and autoradiograms were read using a sonic digitizer (International Biotechnologies, Inc., New Haven, CT). Sequence assembly was performed using a microcomputer and DNA sequence analysis was performed using the University of Wisconsin Genetics Computer Group software.

\section{Results}

A serum containing antibodies against the 60 - and $52-\mathrm{kD}$ components of the SS-A/Ro antigen (Fig. $1 A$ ) was used to screen a $\lambda$ gt $11 \mathrm{cDNA}$ expression library prepared from a MOLT-4 cell line. From screening $\sim 2 \times 10^{6}$ recombinants, one persistent immunoreactive clone, designated $5.1_{\mathrm{a}}$, was isolated. Fig. $1 B$ demonstrates the specific reactivity of SS-A/Ro serum with clone $5.1_{\mathrm{a}}$ in contrast to wild-type $\lambda \mathrm{gt} 11$ (WT) or an irrelevant cDNA bearing phage $\left(3 \mathrm{~J}_{1}\right)$. To identify the serum autoantibodies reactive with clone $5.1_{\mathrm{a}}$, antibodies were affinity purified from the 60- and 52-kD components of HeLa SS-A/Ro, resulting in monospecific anti-60-kD and anti-52-kD antibodies (Fig. $1 A$, lanes 2 and 3). These antibodies were used to probe nitrocellulose filters bearing induced plaques of clone $5.1_{\mathrm{a}}$ or WT $\lambda \mathrm{gt} 11$. Clone $5.1_{\mathrm{a}}$ reacted specifically with anti-60-kD antibodies and failed to react with anti-52-kD antibodies (Fig. $1 C$ ). In a complementary experiment, antibodies that were affinity purified from induced plaques of clone $5.1_{\mathrm{a}}$ specifically immunoblotted a $60-\mathrm{kD}$ HeLa polypeptide (Fig. $1 D$ ). Finally, several sera containing anti-60-kD SS-A/ Ro antibodies reacted with clone $5.1_{\mathrm{a}}$, whereas other autoantisera or normal control sera failed to react (data not shown). Thus, clone $5.1_{\mathrm{a}}$ directs the synthesis of an antigen that shares an epitope(s) with the $60-\mathrm{kD}$, but not the $52-\mathrm{kD}$, component of SS-A/Ro.

In vitro transcription and translation yield a $57.5-k D$ protein precipitated by anti-60-kD SS- $A /$ Ro sera. DNA was prepared from phage $5.1_{\mathrm{a}}$ and the cDNA insert, a 1.8-kb Eco RI fragment, was subcloned into the plasmid vector Bluescript for characterization by in vitro transcription and translation. The resultant plasmid, $\mathrm{p} 5.1_{\mathrm{a}}$, was linearized at polylinker restriction sites on either side of the insert, RNA was synthesized in vitro from both the $T_{7}$ and the $T_{3}$ promoters and this RNA was translated in vitro using a rabbit reticulocyte lysate with $\left[{ }^{35} \mathrm{~S}\right]-$ methionine as described in Methods. The $T_{7}$ transcript directed the synthesis of a polypeptide that migrated at $M_{\mathrm{r}} 57.5$ $\mathrm{kD}$ in addition to smaller polypeptides, whereas the complementary $\mathrm{T}_{3}$-derived RNA failed to direct protein synthesis (Fig. $2 \mathrm{~A}$ ). The smaller polypeptides present among p5.1 translation products are presumed to be breakdown fragments or aberrant ribosomal initiation or termination products. A positive control template, bearing a partial cDNA coding for human $\beta$-glucocerebrosidase, produced a polypeptide of appropriate size in the same reaction. To ascertain whether the $57.5-\mathrm{kD}, \mathrm{p} 5.1_{\mathrm{a}}$-derived protein shared antigenic determinants with SS-A/Ro, cDNA 5.1 in vitro translation products were immunoprecipitated with different SS-A/Ro antisera that 


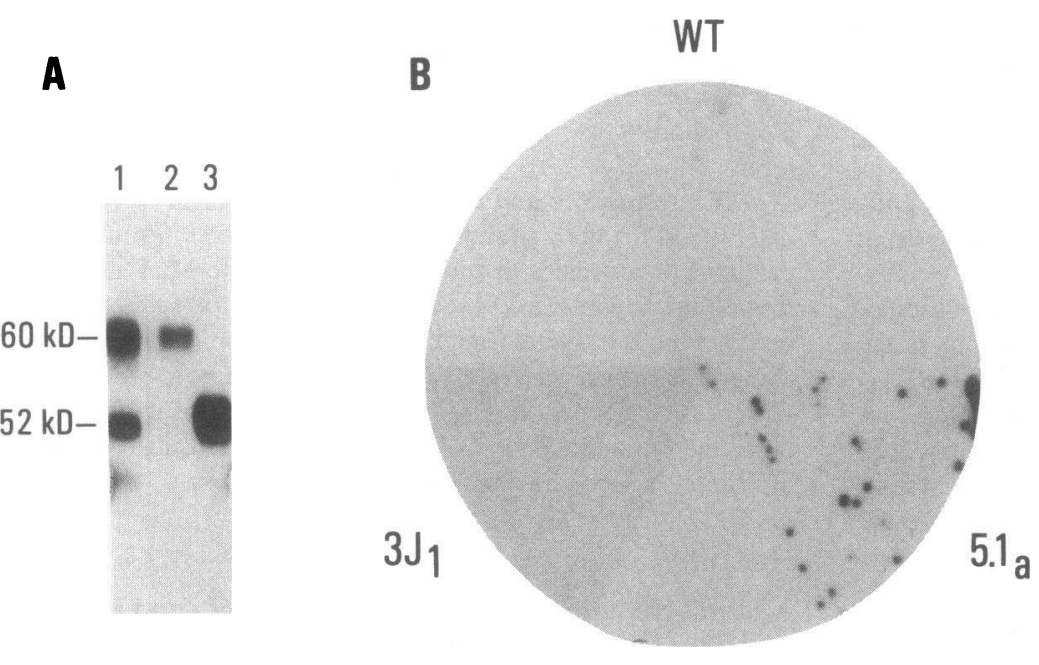

C

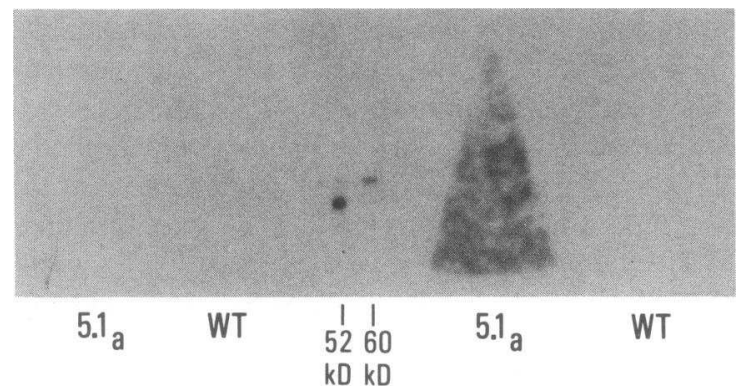

D

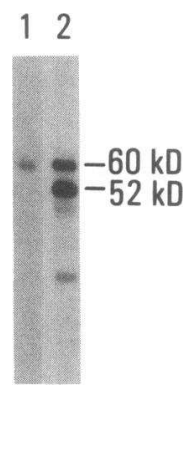

Figure 1. Immunological characterization of the cDNA 5.1 $1_{\mathrm{a}}$ clone. $(A)$ Immunoblot analysis of SS-A/Ro serum. HeLa cell extract was resolved by SDS-PAGE and transferred to nitrocellulose. Strips were cut from the filters and incubated with: lane 1 , whole SS-A/Ro antiserum; lane 2, affinity-purified anti-60-kD antibodies; lane 3 , affinity-purified anti-52-kD antibodies. The serum shown in lane 1 was used for cDNA library screening. (B) Specific reaction of clone $5.1_{\mathrm{a}}$-encoded antigen with SS-A/Ro antiserum. Induced plaques of phage $5.1_{\mathrm{a}}$, WT $\lambda$ gt 11 or an irrelevant cDNA-bearing phage $\left(3 \mathrm{~J}_{1}\right)$ were adsorbed to nitrocellulose filters. Sections of filters were processed for immunodetection using the SS-A/Ro serum shown in $A$. (C) cDNA clone $5.1_{\mathrm{a}}$ reacts uniquely with anti-60-kD SS-A/Ro autoantibodies. Sections of nitrocellulose filters bearing induced plaques of phage $5.1_{\mathrm{a}}$ or $\lambda \mathrm{gt} 11$ (WT) were probed with (left) affinity-purified anti-52-kD antibodies or (right) anti-60-kD antibodies. (Center) Strips of electrophoretically resolved HeLa cell proteins were blotted to demonstrate specificity of affinitypurified antibodies. $(D)$ cDNA clone $5.1_{\mathrm{a}}$-encoded antigen specifically selects anti-60-kD antibodies from SS-A/Ro autoantiserum. Antibodies were affinity purified from SS-A/Ro antiserum using phage $5.1_{\mathrm{a}}$ encoded antigen adsorbed to nitrocellulose as described in Methods and used in immunoblot analysis of HeLa cell proteins. Lane 1, cDNA5. $1_{\mathrm{a}}$-purified antibodies; lane 2 , whole SS-A/Ro antiserum. contained anti-60-kD antibodies, shown in Fig. $2 B$. Sera that precipitated in vivo labeled HeLa SS-A/Ro (lanes 1-3) also precipitated the in vitro synthesized $\mathrm{p} 5.1_{\mathrm{a}}$ protein, as well as some smaller polypeptides (lanes 5-7), whereas a control serum failed to react with either sample (lanes 4 and 8 ). Note that the major translation product of $\mathrm{p} 5.1_{\mathrm{a}}$ migrates with an apparent mass of $57.5 \mathrm{kD}$, slightly faster than the $60-\mathrm{kD}$ HeLa cell SSA-Ro polypeptide, which has an apparent mass of 58.5 $\mathrm{kD}$ under the electrophoretic conditions of Fig. 2.

p5. $1_{a}$ encodes the $60-k D$ component of $S S-A / R o$. The identity of the $\mathrm{p} 5.1_{\mathrm{a}}$ encoded protein was compared with bona fide human SS-A/Ro $60-\mathrm{kD}$ antigen by proteolytic peptide mapping using a modification of Cleveland's protocol (12). $\left[{ }^{35} \mathrm{~S}\right]-$ Methionine-labeled proteins were prepared from HeLa cells by in vivo labeling or from $\mathrm{p} 5.1_{\mathrm{a}}$ by in vitro translation. SS-A/Ro antigens were then purified by immunoprecipitation and SDS-PAGE. Because it was not possible to isolate individual protein bands for analysis, gel strips corresponding to the $M_{\mathrm{r}}$ range of $30-90 \mathrm{kD}$ were sliced from the gel and run transversely on a second set of SDS gels where they were digested with $S$. aureus V8 protease and then developed by fluorography. The results are shown in Fig. 3. The top panels show immunoprecipitation products subjected to electrophoretic procedures without protease, illustrating for HeLa SS-A/Ro the coprecipitation of both the 60 - and 52-kD antigens and for in vitro synthesized products of $\mathrm{p} 5.1_{\mathrm{a}}$, the coprecipitation of the smaller in vitro synthesis products with the $57.5-\mathrm{kD}$ polypeptide. The lower panel shows the polypeptide products obtained after digestion with $S$. aureus V8 protease. The arrows in each panel mark the positions of the 60 - and $57.5-\mathrm{kD}$ proteins. The concordance of peptide products generated from the HeLa $60-\mathrm{kD}$ antigen and the $57.5-\mathrm{kD}$ p5. $1_{\mathrm{a}}$ encoded protein clearly establishes the identity of the $\mathrm{p} 5.1_{\mathrm{a}}$ protein as SS-A/Ro. Conservation of the peptide pattern for smaller $\mathrm{p} 5.1_{\mathrm{a}}$ products verifies that these are breakdown or aberrant translation products of the $60-\mathrm{kD}$ SS-A/Ro antigen. We conclude that $\mathrm{p} 5.1_{\mathrm{a}}$ contains a cDNA possessing the complete or nearly complete coding sequence of the human SS-A/Ro 60-kD antigen.

Nucleotide sequence and deduced amino acid sequences of the $60-k D S S-A /$ Ro protein. The nucleotide sequence of $\mathrm{cDNA}$ $5.1_{\mathrm{a}}$ was determined by the dideoxy method using a series of overlapping Bal-31 deletions subcloned in M13 (14). The complete sequence of 1,863 nucleotides is shown in Fig. $4 \mathrm{~A}$, with the deduced amino acid sequence. A single open reading frame extends from nucleotide 2 to a stop codon at nucleotide 1,760 , potentially encoding 586 amino acids with a predicted molecular mass of $66.2 \mathrm{kD}$. No other reading frame in the sequence is capable of encoding a polypeptide $>7.5 \mathrm{kD}$ and since cDNA $5.1_{\mathrm{a}}$ directs the synthesis of a $57.5-\mathrm{kD}$ protein in vitro and in vivo (see below), we can confidently assign the correct translational frame for the SS-A/Ro $60-\mathrm{kD}$ protein as the one shown in Fig. $4 \mathrm{~A}$. In the absence of amino-terminal 
A

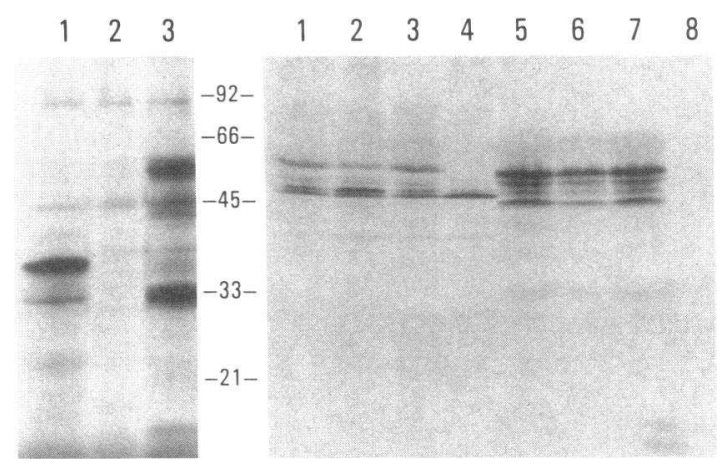

Figure 2. In vitro translation of cDNA 5.1 ${ }_{\mathrm{a}}$-derived RNA. RNA was synthesized in vitro with bacteriophage $T_{3}$ or $T_{7}$ RNA polymerase and used to program in vitro translation in a rabbit reticulocyte lysate. $(A)$ Whole translation products were analyzed by SDS-gel electrophoresis and fluorography. Lane 1 , control translation of a partial cDNA encoding human $\beta$-glucocerebrosidase; lane $2, \mathrm{p} 5.1_{\mathrm{a}} \mathrm{T}_{3}$ promoter transcript; lane 3, p5.1 $\mathrm{a}_{7}$ promoter transcript. (B) Immunoprecipitation of $\mathrm{p} 5.1_{\mathrm{a}}$ in vitro translation products and $\mathrm{HeLa} 60-\mathrm{kD}$ SS-A/Ro antigen. ${ }^{35}$ S-labeled HeLa cell extract $(\sim 2 \mu \mathrm{g} / \mathrm{ml})$ and ${ }^{35} \mathrm{~S}-$ methionine-labeled $\mathrm{p} 5.1_{\mathrm{a}}$ translation products were immunoprecipitated with human sera adsorbed to protein-A Sepharose. Bound proteins were eluted by boiling in SDS-gel sample buffer and analyzed by SDS-PAGE. Lanes 1-3, HeLa cell proteins immunoprecipitated with three different SS-A/Ro antisera; lanes $5-7$, p5.1 $1_{\mathrm{a}}$ in vitro translation products immunoprecipitated with the same sera used in lanes $1-3$, respectively; lanes 4 and 8 , control immunoprecipitation with normal human serum of HeLa cell extract (lane 4) and p5.1 a products (lane 8 ).

protein sequence data it is not possible to determine whether cDNA $5.1_{\mathrm{a}}$ possesses a full-length protein coding region. However, the first in-frame ATG codon at nucleotide 185 initiates a coding region that extends for 1,575 nucleotides, encoding a polypeptide of 525 amino acids with a predicted $M_{\mathrm{r}}$ of 59,241 , similar to the size observed for SS-A/Ro isolated from human cells (see Discussion). The coding region is followed by a $3^{\prime}$ untranslated region of 89 nucleotides, containing a canonical polyadenylation signal, AATAAA $(15,16)$, at nucleotide 1,833 .

No extensive similarity with known proteins or coding sequences in the NBRF and GenBank databases was detected, nor was any overall similarity observed on comparison with other RNP-associated autoantigens, including SS-B/La (17, 18), U1snRNA-associated A protein, U2snRNA-associated B" protein (19) or the U1snRNP-associated 70-kD antigen (20). However, several features of the protein sequence are notable. The RNA-binding protein consensus sequences $\mathrm{RNP}_{1}$ and $\mathrm{RNP}_{2}$ defined by Dreyfuss et al. (21) were found within the SS-A/Ro 60-kD antigen (Fig. 4 B). Another feature is a structure similar to a zinc-finger motif, observed between residues 305-323. This sequence, $\mathrm{C}-\mathrm{X}_{3}-\mathrm{C}-\mathrm{X}_{10}-\mathrm{H}-\mathrm{X}_{2} \mathrm{H}$, occurs in a region of predicted secondary structure similar to that proposed for zinc-fingers in DNA binding proteins (22).

Bacterially expressed $S S-A / R o$ is a sensitive reagent for detection of anti-60-kD SS-A/Ro antibodies. To develop a reagent for sensitive and specific detection of SS-A/Ro autoantibodies in patient sera, the expression of cDNA $5.1_{\mathrm{a}}$ in bacteria

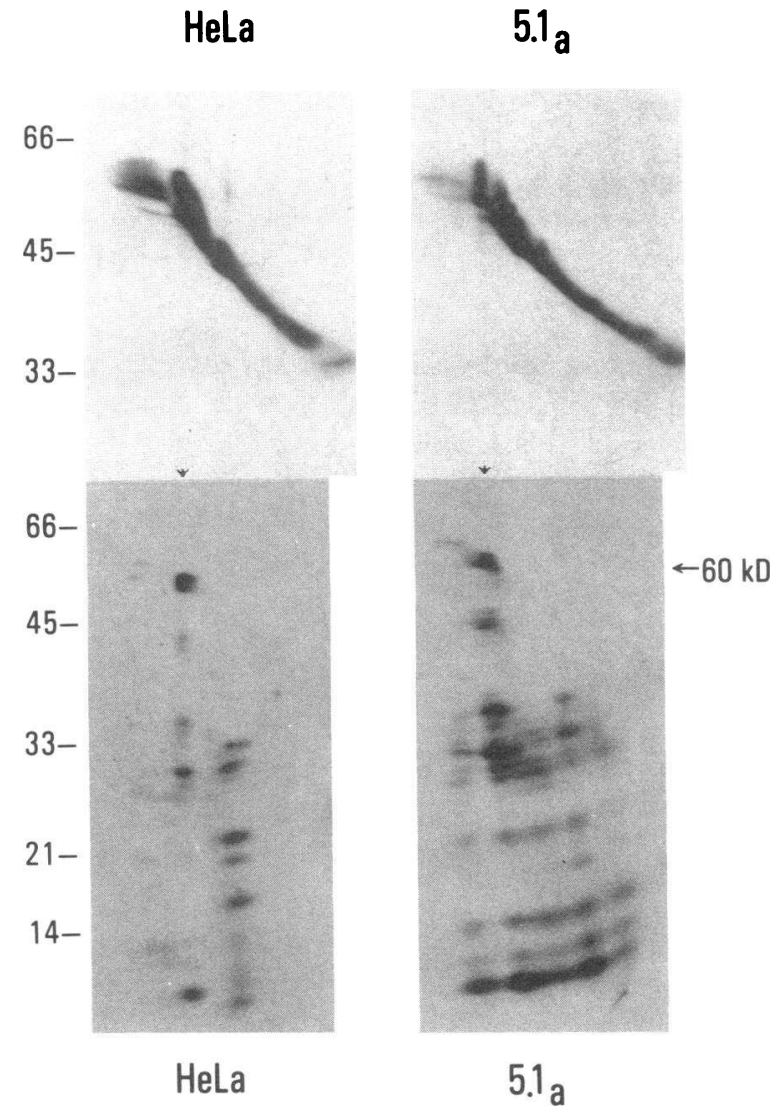

Figure 3. Peptide mapping of the cellular and the in vitro translated protein. $\left[{ }^{35} \mathrm{~S}\right]$ Methionine-labeled proteins were prepared from $\mathrm{p} 5.1_{\mathrm{a}}$ and HeLa cells as described and purified by immunoprecipitation. Immunoprecipitation products were resolved by SDS-PAGE and the regions of the gel corresponding to $M_{\mathrm{r}} 30-90 \mathrm{kD}$ were sliced from each gel and run transversely on a second SDS gel in (top) the absence or (bottom) presence of $S$. aureus V8 protease. (Top) Products obtained by immunoprecipitation of (left) $\mathrm{HeLa}$ and (right) p $5.1_{\mathrm{a}}$ proteins subjected to both electrophoretic procedures without protease digestion. The $60-\mathrm{kD}$ SS-A/Ro antigen from HeLa cell extract coprecipitated with $52-\mathrm{kD}$ antigen and contaminating actin. In vitro translated $\mathrm{p} 5.1_{\mathrm{a}}$-derived $57.5-\mathrm{kD}$ protein coprecipitated with a number of other smaller products. (Bottom) Proteolytic products of both HeLa and 5.1 $\mathrm{a}_{\mathrm{a}}$-derived proteins. Arrowheads, positions of the 60and $57.5-\mathrm{kD}$ protein and proteolytic products.

was examined. A lysogen was constructed from phage $5.1_{\mathrm{a}}$ in $E$. coli $(\mathrm{Y} 1089)$ and recombinant protein synthesis was induced as described in Methods. Crude bacterial lysates were then resolved by electrophoresis and transferred to nitrocellulose filters for immunoblot analysis with a variety of human sera, shown in Fig. 5. Surprisingly, lysogens expressing cDNA $5.1_{\mathrm{a}}$ produced antigenic polypeptides of $M_{\mathrm{r}} 57,500$ and 50,000 in SDS-PAGE instead of the expected $\sim 175-\mathrm{kD}$ fusion protein. To test the possibility that this result was an artifact of the $\beta$-galactosidase fusion, cDNA 5.1 a was subcloned into the trpE fusion protein vector, pATH11, in the same translational frame as the $\beta$-galactosidase construct in $\lambda$ gt 11 with identical results (data not shown). Inspection of the cDNA sequence revealed that the open reading frame of $\mathrm{p} 5.1_{\mathrm{a}}$ is not in frame with the fusion proteins and that a stop codon is present at 


\section{A}

CACAGGCCGACGTCGAGAGGGCCTGCTTTACTCCTCCTCTTTCTCCTCCTTCTCCCGCGGCTTCTGCGCGAGAGGCGTCGCCGGGATCTGGGTTTTGGAAGAAGGATCTTTGTGGGAAGA 120 I $\begin{array}{lllllllllllllllllllllllllllllllllllllllllll}T & G & R & R & R & E & G & L & L & Y & S & S & S & F & S & S & F & S & R & G & F & C & A & R & G & V & A & G & I & W & V & L & E & E & G & S & L & W & E & D\end{array}$ CAGGGTGAATTTATCACAGAGGAATAACGAGGGAGAGGAGAAAGGTTTCCTAAAGACAAAAAAAATGGAGGAATCTGTAAACCAAATGCAGCCACTGAATGAGAAGCAGATAGCCAATTC 240

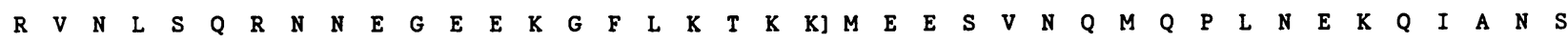
TCAGGATGGATATGTATGGCAAGTCACTGACATGAATCGACTACACCGGTTCTTATGTTTCGGTTCTGAAGGTGGGACTTATTATATCAAAGAACAGAAGTTGGGCCTTGAAAATGCTGA 360

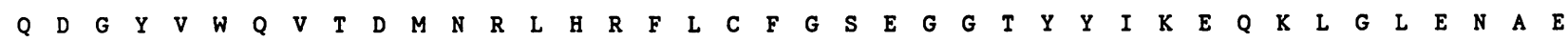
AGCTTTAATTAGATTGATTGAAGATGGCAGAGGATGTGAAGTGATACAAGAAATAAAGTCATTTAGTCAAGAAGGCAGAACCACAAAGCAAGAGCCTATGCTCTTTGCACTTGCCATTTG 480 $\begin{array}{llllllllllllllllllllllllllllllllllllllllllllll}A & L & I & R & L & I & E & D & G & R & G & C & E & V & I & Q & E & I & K & S & F & S & Q & E & G & R & T & T & K & Q & E & P & M & L & F & A & L & A & I & C\end{array}$ RNP2

TTCCCAGTGCTCCGACATAAGCACAAAACAAGCAGCATTTAAAGCTGTTTCTGAAGTTTGTCGCATTCCTACCCATCTCTTTACTTTTATCCAGTTTAAGAAAGATCTGAAGGAAAGCAT 600 $\begin{array}{lllllllllllllllllllllllllllllllllllllllll}S & Q & C & S & D & I & S & T & K & Q & A & A & F & K & A & V & S & E & V & C & R & I & P & T & E & L & F & T & F & I & Q & F & K & K & D & L & K & E & S & M\end{array}$ RNP1

GAAATGTGGCATGTGGGGTCGTGCCCTCCGGAAGGCTATAGCGGACTGGTACAATGAGAAAGGTGGCATGGCCCTTGCTCTGGCAGTTACAAAATATAAACAGAGAAATGGCTGGTCTCA 720 $\begin{array}{lllllllllllllllllllllllllllllllllllllllll}K & C & G & M & W & G & R & A & L & R & K & A & I & A & D & W & Y & N & E & K & G & G & M & A & L & A & L & A & V & T & K & Y & K & Q & R & N & G & W & S & H\end{array}$ CAAAGATCTATTAAGATTGTCACATCTTAAACCTTCCAGTGAAGGACTTGCAATTGTGACCAAATATATTACAAAGGGCTGGAAAGAAGTTCATGAATTGTATAAAGAAAAAGCACTCTC 840 $\begin{array}{llllllllllllllllllllllllllllllllllllllllll}\text { K } & \text { D } & \text { L } & \text { L } & \text { R } & \text { L } & \text { S } & \text { H } & \text { L } & \text { K } & \text { P } & \text { S } & \text { S } & \text { E } & G & \text { L } & \text { A } & \text { I } & \text { V } & \text { T } & \text { K } & \text { Y } & \text { I } & \text { T } & \text { K } & \text { G } & \text { W } & \text { K } & \text { E } & \text { V } & \text { H } & \text { E } & \text { L } & \text { Y } & \text { K } & \text { E } & \text { K } & \text { A } & \text { L } & \text { S }\end{array}$ TGTGGAGACTGAAAAATTATTAAAGTATCTGGAGGCTGTAGAGAAAGTGAAGCGCACAAGAGATGAGCTAGAAGTCATTCATCTAATAGAAGAACATAGATTAGTTAGAGAACATCTTTT 960

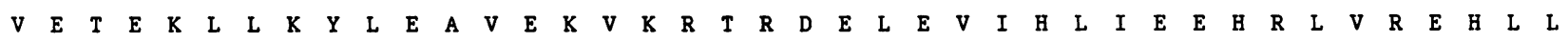
AACAAATCACTTAAAGTCTAAAGAGGTATGGAAGGCTTTGTTACAAGAAATGCCGCTTACTGCATTACTAAGGAATCTAGGAAAGATGACTGCTAATTCAGATGTTGAACCAGGAAATTC 1080 $\begin{array}{llllllllllllllllllllllllllllllllllllllll}\text { T } & \text { N } & \text { H } & \text { L } & \text { K } & \text { S } & \text { K } & \text { E } & \text { V } & \text { W } & \text { K } & \text { A } & \text { L } & \text { L } & \text { Q } & \text { E } & \text { M } & \text { P } & \text { L } & \text { I } & \text { A } & \text { L } & \text { L } & \text { R } & \text { N } & \text { L } & \text { G } & \text { K } & \text { M } & \text { T } & \text { A } & \text { N } & \text { S } & \text { D } & \text { V } & \text { E } & \text { P } & G & \text { N } & \text { S }\end{array}$ AGAAGCATCTTTAGTATGTGAAAACTGTGTAATGAAAAACTATTAAAAAAGGCTCGTATACATCCATTTCATATTTTGATCGCATTAGAAACTTACAAGACAGGTCATGGTCTCAGAGG 1200

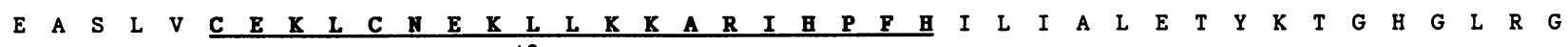
$\mathrm{zn}+2$ FINGER MOTIF

GAAACTGAAGTGGCGCCTTGATGAAGAAATTTTGAAAGCATTGGATGCTGCTTTTTATAAAACATTTAAGACAGTTGAACCAACTGGAAAACGTTTCTTACTAGCTGTTGATGTCAGTGC 1320

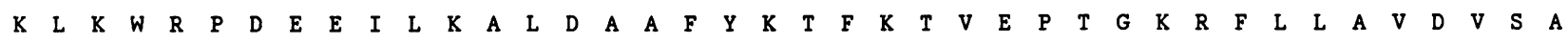

TTCTATGAACCAAAGAGTTTTGGGTAGTATACTCAACGCTAGTACAGTTGCTGCAGCAATGTGCATGGTTGTCACACGAACAGAAAAAGATTCTTATGTAGTTGCTTTTTCCGATGAAAT 1440 $\begin{array}{llllllllllllllllllllllllllllllllllllllllll}S & M & N & Q & R & V & L & G & S & I & L & N & A & S & T & V & A & A & A & M & C & M & V & V & T & R & T & E & K & D & S & Y & V & V & A & F & S & D & E & M\end{array}$ GGTACCATGTCCAGTGACTACAGATATGACCTTACAACAGGTTTTAATGGCTATGAGTCAGATCCCAGCAGGTGGAACTGATTGCTCTCTTCCAATGATCTGGGCTCAGAAGACAAACAC 1560

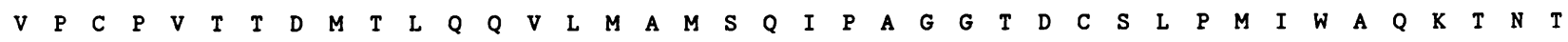

ACCTGCTGATGTCTTCATTGTATTCACTGATAATGAGACCTTTGCTGGAGGTGTCCATCCTGCTATTGCTCTGAGGGAGTATCGAAAGAAAATGGATATTCCAGCTAAATTGATTGTTTG 1680

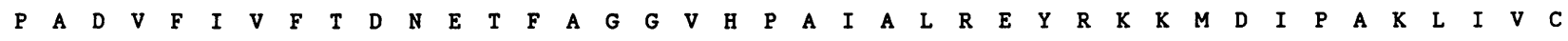

TGGAATGACATCAAATGGTTTCACCATTGCAGACCCAGATGATAGAGCCTTGCAAAATACCCTACTAAATAAATCATTTTAGACATGGAGTGCAGGTGGACACTGTGTGAACTGTTTTTG 1800

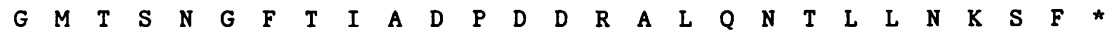
GTCAGTTATTGTAGAAATTGATAGATGTACCAAATAAACTCTATGCACATTA (11) 
B

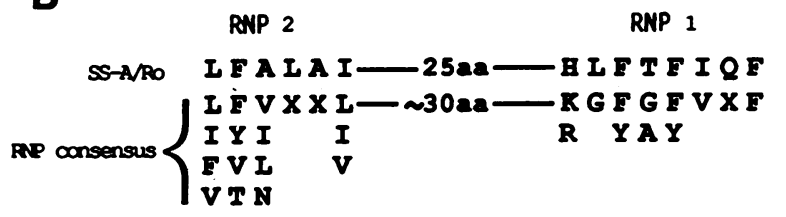

Figure 4. Nucleic acid sequence of the cDNA insert of clone $5.1_{\mathrm{a}}$ and the predicted amino acid sequence. $(A)$ (Top) Nucleotide and (bottom) predicted amino acid residues are numbered at the right of each line. Translation of the sequence $5^{\prime}$ to $\mathrm{ATG}_{185}$ is enclosed in brackets as it is unclear whether this sequence is translated in vivo. The consensus RNA-binding sequences RNP1 and RNP2 and the zinc-finger motif are underlined. $(B)$ Comparison of residues 93-131 of the SS-A/Ro 60-kD antigen with the RNP consensus sequence defined by Dreyfuss and co-workers (21).

nucleotide 126 in the translational frame of the fusion protein. Further, a sequence similar to the Shine-Dalgarno (S/D) ribosome binding site for $E$. coli translation, GAGGAGAA, is observed at position 155, 23 nucleotides upstream of the first ATG codon (23). This is diagrammed in Fig. 6. Thus, for the fusion constructs examined in this work, it appears translation terminates at the stop codon upstream of the SSA/Ro coding region and efficiently reinitiates at $\mathrm{ATG}_{185}$, resulting in the synthesis of the $57.5-\mathrm{kD}$ protein. It is not clear whether the $50-\mathrm{kD}$ band represents a major degradation product of the $57.5-\mathrm{kD}$ polypeptide or whether it represents use of an alternate translational initiation site. Both the $57.5-$ and $50-\mathrm{kD}$ polypeptides were reactive with $>15$ sera containing anti-60kD SS-A/Ro antibodies and with the affinity-purified anti-60kD antibodies (Fig. 5).

The specificity of antibody reactivity with SS-A/Ro sera was tested by parallel immunoblots with sera of other autoantibody specificities. Sera containing anti-Sm, RNP, proliferating cell nuclear antigen (Fig. $5 \mathrm{D}$ ), and sera with anti-SS-B/La or only anti-52-kD antibodies (Fig. $5 B$ ) did not react with bacterially expressed SS-A/Ro. As an additional control we have constructed lysogens containing a cDNA coding partially for the SS-B/La antigen. In immunoblot analysis of the autoantisera against the recombinant SS-B/La antigen, only sera containing anti-SS-B antibodies reacted, whereas anti-SS-A/ Ro or normal human serum did not react (Fig. $5 C$ ).

\section{Discussion}

A serum from a patient with SS was used to isolate a human cDNA clone encoding the $60-\mathrm{kD}$ SS-A/Ro antigen from a Agt11 expression library. The immunological identity of the antigen encoded by cDNA clone $5.1_{\mathrm{a}}$ was established in a series of experiments that showed that the $5.1_{\mathrm{a}}$-derived antigen shared an epitope(s) in common with the $60-\mathrm{kD}$ SS-A/Ro antigen. Antibodies affinity purified from the $60-\mathrm{kD}$ antigen of HeLa cell extract reacted exclusively with phage plaques expressing the 5.1 antigen (Fig. $1 \mathrm{C}$ ). Conversely, antibodies affinity purified from the phage $5.1_{\mathrm{a}}$ encoded antigen specifically recognized a $60-\mathrm{kD}$ polypeptide on immunoblot of total HeLa cell proteins (Fig. 1 D). The immunofluorescence staining pattern observed with cDNA 5.1 1 affinity-purified antibodies was indistinguishable from the staining pattern observed with monospecific anti-60-kD serum (data not shown). The

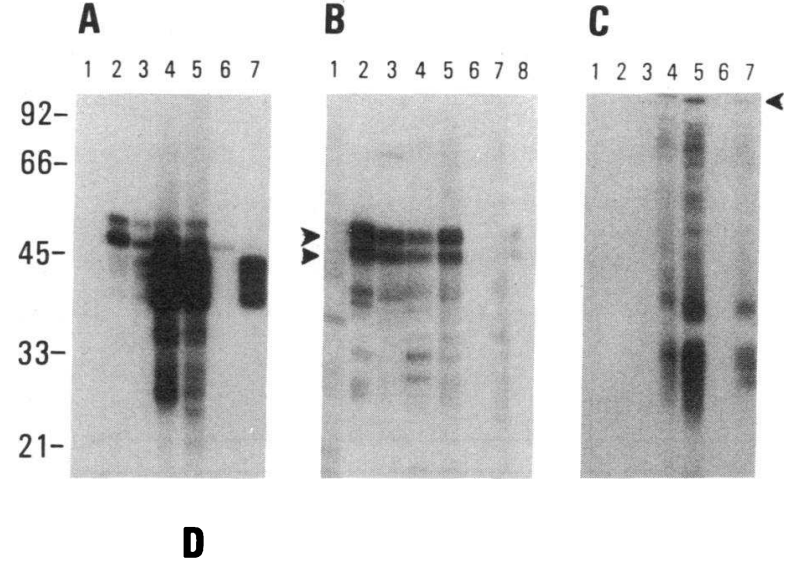

1234456789101112131415161718

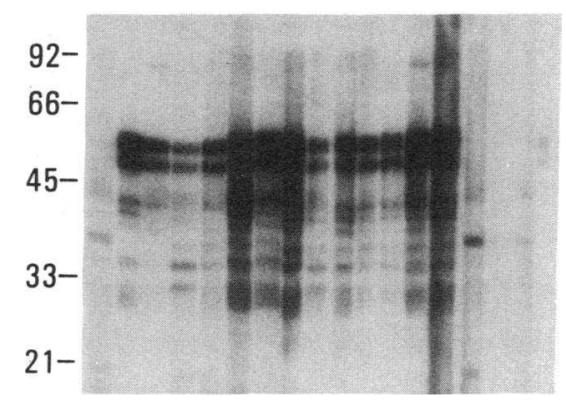

Figure 5. Immunoblot analysis of bacterial lysate containing the p5. $1_{\mathrm{a}}$ cDNA directed protein and MOLT -4 extract containing the 60-kD SS-A/Ro antigen. Crude bacterial lysate derived from induced cultures of $\lambda g t 11$ lysogens and MOLT -4 extract were resolved by SDS-PAGE and transferred to nitrocellulose sheets for immunoblot analysis. Individual nitrocellulose strips were probed with serum of different specificities. In $A, B$, and $C$ each lane represents the same serum. Arrows in $B$, SS-A/Ro recombinant protein and degradation product; arrow in $C$, SS-B/La fusion protein. $(A)$ MOLT-4 extract; $(B), \lambda g t 11-5.1_{\mathrm{a}}$ lysogen extract; $(C)$, lysate of a $\lambda g t 11$ lysogen bearing a partial length CDNA for SS-B/La antigen. Lane 1, normal serum; lanes 2 and 3, SS-A/Ro sera containing anti-60-kD and anti-52-kD antibodies; lanes 4 and 5, SS-A/Ro sera containing anti SS-B/La antibodies and both SS-A/Ro antigens; lane 6, monospecific anti-52kD SS-A/Ro serum; lane 7, monospecific anti-SS-B/La serum; lane 8, ( $B$ only) affinity-purified anti-60-kD SS-A/Ro antibodies. (D) Immunoblot analysis of different patient sera using recombinant SS-A/ Ro 60-kD antigen. Lane 1, normal human serum; lanes 2-14, sera from SLE and SS patients bearing anti-SS-A/Ro antibodies; lane 15, anti-Sm serum; lane 16, anti-RNP serum; lane 17, anti-PCNA serum; lane 18 , affinity-purified anti-60-kD antibodies. Sera were used at a dilution of 1:100.

biochemical identity of the cDNA encoded protein was established by demonstrating the similarity of peptide maps of the in vitro translated protein and the cellular $60-\mathrm{kD}$ SS-A/Ro polypeptide after Staphylococcus aureus V8 protease digestion (Fig. 3). These experiments demonstrate that cDNA 5.1 represents a copy of the mRNA encoding the humar SS-A/Ro 60-kD antigen.

cDNA $5.1_{\mathrm{a}}$ contains a single long open reading frame beginning at nucleotide 2 of the sequence shown in Fig. $4 \mathrm{~A}$. No other translational frame in the sequence encodes a polypeptide $>7.5 \mathrm{kD}$, so we conclude that the reading frame shown is the translational frame for SSA/Ro. Since the ORF extends to 


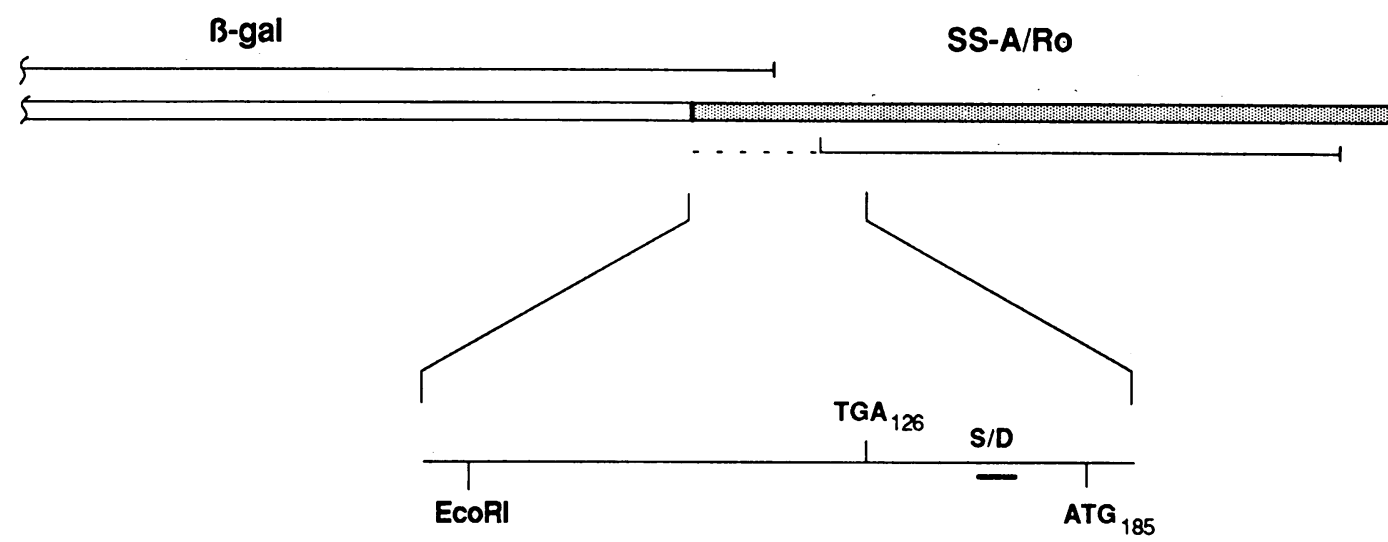

Figure 6. Diagrammatic representation of constructs for expression of cDNA p5. $1_{\mathrm{a}}$ in bacteria. The structure of the $\lambda g t 11-5.1_{\mathrm{a}}$ lysogen is shown. Translation of $\beta$ galactosidase proceeds across the Eco-RI linker of the cDNA in translational frame 3 and terminates at a stop codon 126 nucleotides $3^{\prime}$ of the EcoRI linker. Translation of SS-A/Ro from reading frame 2 of the cDNA initiates at $\mathrm{ATG}_{185}, 23 \mathrm{nu}$ cleotides downstream of a sequence resembling the Shine-Dalgarno ribosome binding site of $E$. coli (S/D in the figure). The resulting protein product is an unfused SS-A/Ro polypeptide with a $M_{\mathrm{r}}$ of $57.5 \mathrm{kD}$. the $5^{\prime}$ end of the cDNA, it is not possible to unequivocally determine whether the cDNA contains a full length coding region for SS-A/Ro. The first in frame ATG codon, at nucleotide 185 , is in a sequence context that corresponds well to a consensus derived from 699 eukaryotic initiator ATG codons (24) and predicts a protein of $\mathrm{M}_{\mathrm{r}} 59.2 \mathrm{kD}$, closely corresponding with the experimentally observed size of $57.5 \mathrm{kD}$ observed by in vitro translation (Fig. 3), expression of cDNA $5.1_{\mathrm{a}}$ in $E$. coli (Fig. $5 \mathrm{~B}$ ) and reported for human SS-A/Ro antigen (3, 25). These data are consistent with cDNA $5.1_{\mathrm{a}}$ possessing a full-length coding region initiating at $\mathrm{ATG}_{185}$, but do not constitute proof that $\mathrm{ATG}_{185}$ initiates SS-A/Ro translation in vivo. Indeed, a slight difference in the apparent relative molecular mass of the in vitro translation product of $\mathrm{p} 5.1_{\mathrm{a}}$ is observed in the experiment shown in Fig. 2. This difference could be due to a posttranslational modification of the SS-A/Ro $60-\mathrm{kD}$ antigen in HeLa cells, or to initiation of bona fide SS-A/Ro $60-\mathrm{kD}$ antigen at an ATG codon not represented on CDNA $5.1_{\mathrm{a}}$. Whereas the latter possibility seems unlikely, because initiation beyond the $5^{\prime}$ end of the p5.1 $1_{\mathrm{a}}$ sequence would contribute at least $8 \mathrm{kD}$ of additional polypeptide sequence, significantly in excess of the observed 1-kD difference in size, unequivocal assignment of the correct initiation site for translation of the $60-\mathrm{kD}$ SS-A/Ro antigen will require further experimental analysis.

Recently, another group has reported the determination of the amino-terminal 16 amino acids of the SS-A/Ro antigen purified by biochemical means from calf thymus (26). Because this sequence lacked an $\mathrm{NH}_{2}$-terminal methionine residue, it would appear to be derived from a proteolytic product of the calf thymus SS-A/Ro antigen. A search for this peptide sequence within the sequence reported here reveals no corresponding region encoded by the human SS-A/Ro cDNA $5.1_{\mathrm{a}}$. Three possible explanations exist for this discrepancy. One is that the cDNA reported here does not possess the entire coding region for SS-A/Ro and that the sequence reported by Lieu and co-workers is present beyond the $5^{\prime}$ end of cDNA $5.1_{\mathrm{a}}$. Another is that the sequence of the human and calf SS-A/Ro proteins have diverged in the amino-terminal region beyond recognizable homology. As a third possibility, in view of the complexity of the antigens recognized by SS-A/Ro sera which include at least the $60-\mathrm{kD}$ protein reported here and a $52-\mathrm{kD}$ antigen (4), it is possible that these workers have isolated the $52-\mathrm{kD}$ antigen or an additional antigenic component of the SS-A/Ro system. Clearly, further experimental work will be required to clarify the relationship of the protein isolated by Lieu and co-workers with the $60-\mathrm{kD}$ SS-A/Ro antigen described here.

Comparison of the predicted sequence of the SS-A/Ro $60-\mathrm{kD}$ protein with other RNA binding proteins such as the U1-snRNP-associated A protein, U2-snRNP-associated B" protein, U1snRNP-associated $70-\mathrm{kD}$ protein and SS-B/La (19, 20) did not reveal any significant global sequence similarity, but did reveal the presence of two sequences defined as RNP consensus sequences (21), detailed in Fig. $4 B$. The most highly conserved sequence, RNP1, differs in SS-A/Ro by the substitution of the amino-terminal dipeptide $\mathrm{KG}$, observed almost invariably among the previously defined RNP proteins, with the dipeptide HL in SS-A/Ro. This suggests that the aromatic residues present in RNP1 are the most highly conserved elements of the sequence, perhaps involved in interaction with the heterocyclic bases of the bound RNA. The second provocative feature of the SS-A/Ro sequence is the presence of a sequence similar to a single zinc-finger motif, shown in Fig. 4 $A$. This motif has been observed in a number of DNA binding proteins that serve as transcriptional regulatory elements and has been shown to be responsible for the sequence-specific DNA binding activity of several polypeptides (27). Among 
known DNA binding proteins, the classical $\mathrm{C}_{2} \mathrm{H}_{2}$ type zincfinger motif is repeated at least two and as many as 13 times within the protein (27). In the case of SS-A/Ro, there is only one zinc-finger motif. It is not known whether SS-A/Ro binds DNA or divalent metal cations and so the significance of the observed zinc-finger motif remains to be experimentally evaluated.

The biological function of the SS-A/Ro RNP is not known. It has been suggested that it might play a role in the control of the distribution of mRNAs into translationally active or inactive forms (28). It has also been reported that the SS-A/Ro antigen may be a part of a cellular complex possessing endoribonuclease VII activity (29). The fact that the $60-\mathrm{kD}$ SS-A/Ro protein contains a zinc-finger motif, potentially capable of binding DNA, in addition to the putative RNA-binding domains RNP1 and RNP2 may suggest that the $60-\mathrm{kD}$ SS-A/Ro protein resembles transcription factor IIIA, which is able to bind both DNA and RNA (22) and might therefore play a role in transcriptional regulation. It will now be possible to develop experimental systems to test the structure and function of the SS-A/Ro $60-\mathrm{kD}$ polypeptide using the cDNA reported here.

From a clinical point of view, the work reported here represents a significant step in understanding the autoimmune reaction against SS-A/Ro observed in various rheumatic diseases. Mapping the epitope(s) reacting with the anti-SS-A/Ro antibodies may shed light on the question of whether these polypeptides share a special or common motif characteristic to autoantigens. Furthermore, since the cellular amount of the SS-A/Ro protein is relatively low and its purification is difficult, the availability of the cDNA is advantageous. It can be prepared in large scale using bacterially expressed vectors where no other human autoantigens exist. This may allow analysis of sera from patients with rheumatic diseases by immunoblotting or ELISA, using purer substrate for more sensitive and accurate assays than the current available methods.

In summary, this report described the isolation, and expression of the $60-\mathrm{kD}$ SS-A/Ro antigen. Analysis of its sequence revealed the presence of putative RNA and DNA binding sites, which may yield insights to its intracellular role. The availability of the clone may also be helpful in producing a pure antigen for screening patients for their antibody profiles and to further study the autoimmune response.

\section{Acknowledgments}

The authors would like to thank Dr. Jack C. Keene for his generosity in sharing unpublished data concerning the sequence of an SS-A/Ro cDNA isolated in his laboratory.

This work was supported in part by grants AR-32063 and AR-33489. K. F. Sullivan is a Hulda Irene Dugan Investigator of the Arthritis Foundation. This is publication number 5335BCR from the Research Institute of Scripps Clinic, La Jolla, California.

\section{References}

1. Tan, E. M. 1982. Autoantibodies to nuclear antigens (ANA): their immunobiology and medicine. Adv. Immunol. 33:167-240.

2. Theofilopoulos, A. N., and F. J. Dixon. 1979. The biology and detection of immune complexes. Adv. Immunol. 28:89-220.

3. Wolin, S. L., and J. A. Steitz. 1984. The Ro small cytoplasmic ribonucleoproteins: identification of the antigenic protein binding site on the Ro RNAs. Proc. Natl. Acad. Sci. USA. 81:1996-2000.

4. Ben-Chetrit, E., E. K. L. Chan, K. F. Sullivan, and E. M. Tan. 1988. A 52-kD protein is a novel component of the SS-A/Ro antigenic particle. J. Exp. Med. 167:1560-1572.

5. Towbin, H., T. Staehelin, and J. Gordon. 1979. Electrophoretic transfer of proteins from polyacrylamide gels to nitrocellulose sheets: procedure and some applications. Proc. Natl. Acad. Sci. USA. 76:4350-4354.

6. Chan, E. K. L., A. M. Francoeur, and E. M. Tan. 1986. Epitopes, structural domains and asymmetry of amino acid residues in SS-B/La nuclear protein. J. Immunol. 136:3744-3749.

7. Olmsted, J. B. 1981. Affinity purification of antibodies from diazotized paper blots of heterogeneous protein samples. J. Biol. Chem. 256:11955-11957.

8. Young, R. Y., and R. W. Davis. 1983. Yeast RNA polymerase II genes: isolation with antibody probes. Science (Wash. DC). 222:778782.

9. Earnshaw, W. C., K. F. Sullivan, P. S. Machlin, C. A. Cooke, D. A. Kaiser, T. D. Pollard, N. F. Rothfield, and D. W. Cleveland. 1987. Molecular cloning of CDNA for CENP-B, the major human centromere autoantigen. J. Cell Biol. 104:817-829.

10. Spindler, K. R., D. S. Rosser, and A. J. Berk. 1984. Analysis of adenovirus transforming proteins from early regions $1 \mathrm{~A}$ and $1 \mathrm{~B}$ with antisera to inducible fusion antigens produced in Escherichia coli. $J$. Virol. 49:132-141.

11. Konarska, M. M., P. J. Grabowski, R. A. Padgett, and P. A. Sharp. 1985. Characterization of the branch site in lariat RNAs produced by splicing of mRNA precursors. Nature (Lond.). 313:552-557.

12. Cleveland, D. W., S. G. Fisher, M. W. Kirschner, and U. K. Laemmli. 1977. Peptide mapping by limited proteolysis in sodium dodecyl sulfate and analysis by gel electrophoresis. J. Biol. Chem. 252:1102-1106.

13. Sullivan, K. F., P. S. Machlin, H. Ratrie, and D. W. Cleveland. 1986. Sequence and expression of the chicken beta-3 tubulin gene. $J$. Biol. Chem. 261:13317-13322.

14. Sanger, F. 1981. Determination of nucleotide sequence in DNA. Science (Wash. DC). 214:1205-1210.

15. Proudfoot, N. J., and G. G. Brownlee. 1976. 3' non-coding region sequences in eukaryotic messenger RNA. Nature (Lond.). 263:211-214.

16. Leff, S. E., M. G. Rosenfeld, and R. M. Evans. 1986. Complex transcriptional units: diversity in gene expression by alternative RNA processing. Annu. Rev. Biochem. 55:1091-1117.

17. Sturgess, A. D., M. G. Peterson, L. J. McNeilage, S. Whittingham, and R. L. Coppel. 1988. Characteristics and epitope mapping of a cloned human autoantigen La. J. Immunol. 140:3212-3218.

18. Chambers, J. C., D. Kenan, B. J. Martin, and J. D. Keene. 1988. Genomic structure and amino acid sequence domains of the human La autoantigen. J. Biol. Chem. 263:18043-18051.

19. Sillekens, P. T. G., W. J. Habets, R. P. Beijer, and W. J. van Venrooij. 1987. cDNA cloning of the human U-1 mRNA-associated a protein: extensive homology between U-1 and U-2 mRNP-specific proteins. EMBO (Eur. Mol. Biol. Organ.) J. 6:3841-3848.

20. Thiessen, H., M. Etzerodt, R. Reuter, C. Schneider, F. Lottspeich, P. Argos, R. Luhrmann, and L. Philipson. 1986. Cloning of the human cDNA for the U-1 RNA-associated $75 \mathrm{~K}$ protein. EMBO (Eur. Mol. Biol. Organ.) J. 5:3209-3217.

21. Dreyfuss, G., M. S. Swanson, and S. Pinol-Roma. 1988. Heterogeneous nuclear ribonucleoprotein particles and the pathway of mRNA formation. Trends Biochem. Sci. 13:86-91.

22. Miller, J., A. D. McLachlan, and A. Klug. 1985. Repetitive zinc-binding domains in the protein transcription factor III A from Xenopus oocytes. EMBO (Eur. Mol. Biol. Organ.) J. 4:1609-1614.

23. Shine, J., and L. Dalgarno. 1974. The 3'-terminal sequence of Escherichia coli $16 \mathrm{~S}$ ribosomal RNA: complementarity to nonsense 
triplets and ribosone binding sites. Proc. Natl. Acad. Sci. USA. 71:1342-1346.

24. Kozak, M. 1987. An analysis of 5'-noncoding sequences from 699 vertebrate messenger RNAs. Nucleic Acids Res. 15:8125-8148.

25. Elkon, K. B., and P. W. Jankowski. 1985. Five specificities of autoantibodies directed against the $\mathrm{Ro}, \mathrm{La}, \mathrm{Sm}, \mathrm{RNP}$ and To-1 proteins defined by two dimensional gel electrophoresis and immunoblotting. J. Immunol. 134:3819-3824.

26. Lieu, T. S., M. M. Newkirk, J. D. Capra, and R. D. Sontheimer. 1987. Molecular characterization of the human Ro/SS-A antigen. Amino-terminal sequence of the protein moiety of human Ro/SSA antigen and immunological activity of a corresponding synthetic peptide. J. Clin. Invest. 82:96-101.

27. Evans, R. M., and S. M. Hollenberg. 1988. Zinc fingers: gilt by association. Cell. 52:1-3.

28. Kato, N., H. Hosino, and F. Harada. 1982. Nucleotide sequence of 4.5 S RNA (C8 or hy5) from hela cells. Biochem. Biophys. Res. Commun. 108:363-370.

29. Bachmann, M., W. J. Mayet, H. C. Schroder, K. Pfeifer, Z. Meyer, K. H. Buschenfelde, and W. E. G. Muller. 1987. Identification of the Ro and La antigens in the endoribonuclease VII-ribonucleoprotein complex. Biochem. J. 243:189-194. 